\title{
New records of Oleoguttula mirabilis and Rachicladosporium antarcticum from James Ross Island, Antarctica
}

\author{
Monika Laichmanová
}

Department of Experimental Biology, Czech Collection of Microorganisms, Faculty of Science, Masaryk University, Kamenice 5, 62500 Brno, Czech Republic

\begin{abstract}
A group of seven isolates of black meristematic fungi was collected from rocks within the framework of mycological research focused on the study of diversity of rockinhabiting fungi on James Ross Island in Antarctica. Their identification was based on ITS rDNA sequence comparisons supported by morphological data. Obtained results assigned four analysed strains as Oleoguttula mirabilis and three isolates as Rachicladosporium antarcticum. To the best of our knowledge this is the second report of isolation of these two psychrophilic species from different parts of James Ross Island which imply that they probably represent a common part of its environmental microbial flora.
\end{abstract}

Key words: black yeast, ITS rDNA region, meristematic fungi, polar region, rockinhabiting fungi

DOI: $10.5817 / \mathrm{CPR} 2020-2-17$

\section{Introduction}

Rock-inhabiting fungi (RIF) represent a polyphyletic group of extremotolerant microorganisms which occur in different inhospitable environment such as cold or hot deserts (Ruibal et al. 2005, 2008; Selbmann et al. 2005, 2008, 2013, 2014; Egidi et al. 2014). Except natural habitats, a number of species have been isolated from marble monuments (Wollenzien et al. 1995, Sert et al. 2007, Isola et al. 2015) or radiation-ravaged places (Zhdanova et al. 2000).

Antarctic rocks represent harsh habitat due to the presence of various stress factors, including nutrient deficiency, intense sunlight, high UV radiation, osmotic stress, temperature fluctuations or low water availability (Sterflinger 1998, 2006; Selbmann et al. 2008, 2011). Despite those adverse conditions, they are inhabited by various

Received November 26, 2020, accepted December 29, 2020.

*Corresponding author: M. Laichmanová <monikadr@sci.muni.cz>

Acknowledgements: The author wish to thank the scientific infrastructure of the J. G. Mendel Czech Antarctic Station, part of the Czech Polar Research Infrastructure (CzechPolar2), and its crew for their assistance, supported by the Ministry of Education, Youth and Sports of the Czech Republic (LM2015078) and the Czech Antarctic Foundation for their support. Sincere thanks go to Dr. Pavel Švec for his valuable comments on the manuscript and Dr. Zdeněk Stachoň for providing topographic data. 
microbial communities including algae, bacteria, cyanobacteria, lichenised and nonlichenised fungi. Fungi colonise rocks on the surface (epilithic fungi) and/or inside the rock (endolithic fungi)(Friedmann 1982, Selbmann et al. 2005, 2013; Gorbushina 2007, Zucconi et al. 2014).

The ability of these fungi to survive in extreme conditions is given by their morpho-physiological properties. They are characterized by restricted growth leading to formation of small compact black colonies. The black coloration of cells is given by production of high amount of pigment melanin, which protects them against UV radiation (Selbmann et al. 2005, 2011). Meristematic growth characterised by isodiametrically dividing cells contributes to their resistance as well and enable them to survive desiccation and extreme temperatures (Urzì et al. 2000, Selbmann et al. 2005).

Many novel genera of RIF, such as Cryomyces, Elasticomyces, Extremus, Oleoguttula, Recurvomyces, Vermiconidia, and endemic genus Friedmanniomyces have been described from the cold environment of Antarctica in taxonomic papers of Selbmann et al. $(2005,2008)$ and Egidi et al. (2014). They are classified into the class Dothideomycetes, mainly within the order Capnodiales (Ruibal et al. 2009, Egidi et al. 2014, Quaedvlieg et al. 2014).

The genus Oleoguttula belongs to the family Teratosphaeriaceae within the order Capnodiales (Egidi et. al. 2014, Quaedvlieg et al. 2014) The genus represented by a single psychrophilic species Oleoguttula mirabilis was proposed based on two isolates originated from rocks on James Ross Island by Selbmann and de Hoog (Egidi et. al. 2014) and the name was validated by Crous et al. (2019). Recently, this species has also been recorded from ice with high ice algae abundance (called dark ice) from Greenland Ice Sheet (Perini et al. 2019). Phialidic conidiogenesis is the important morphological feature of this genus, which has not been observed in other RIF taxa described from Antarctica and makes this species easy to distinguish from remaining RIF species (Egidi et. al. 2014).

The genus Rachicladosporium belongs to the order Capnodiales and family Cladosporiaceae with phylogenetically closely related genera Cladosporium, Dichocladosporium, Toxicocladosporium and Verrucocladosporium. It was proposed by Crous et al. (2007) on a single isolate from leaf spots on Luculia sp. and assigned as Rachicladosporium luculiae. At present the genus comprise 14 species with validly published name that accommodate mainly epiphytic and rock-inhabiting fungi. A total, six new mostly psychrophilic species were described from rocks of which three species originated from the Italian Alps and two species from Antarctica, namely Rachicladosporium mcmurdoi and Rachicladosporium antarcticum (Egidi et al. 2014, Crous et al. 2019). Rachicladosporium is morphologically distinguishable from Cladosporium s. str. and related cladosporium-like genera by presence of apical rachis on conidiophores with inconspicuous to subconspicuous scars and unthickened, not darkened-refractive conidial hila (Crous et al. 2007). In contrast the rock-inhabiting species usually produce brown septate hyphae only, cladosporiumlike cells are not observed (Egidi et al. 2014).

Morphological identification of many RIF species is difficult because some of them are highly pleomorphic or many species are morphologically scarcely differentiated and meristematic growth presents the only type of their reproduction (Urzì et al. 2000, Egidi et al. 2014). Therefore their identification is based primarily on phylogenetic analysis supported by morphological data.

In total, 115 isolates of black meristematic fungi were collected from rocks within the framework of mycological research focused on the study of diversity, taxonomy and phylogenetic relationships of rock-inhabiting fungi inhabiting James 
Ross Island in Antarctica. For most isolates there were no phylogenetically close ITS rDNA sequences available in the GenBank nucleotide database enabling their reliable taxonomic identification (unpublished). Only seven RIF isolates de-

\section{Material and Methods}

\section{Sampling sites}

The investigated area was located in the northern deglaciated part of the Ulu Peninsula, James Ross Island (64 $14^{\circ} \mathrm{S}$, $\left.57^{\circ} 45^{\prime} \mathrm{W}\right)$, which is situated close to the northeastern extremity of the Antarctic Peninsula. The climate of the island is semiarid with the mean annual tempera-

\section{Sampling and isolation}

Seven isolates of RIF analysed in this study were obtained from five samples of rock fragments collected in February and March during the Czech polar expedition in 2018. The rock samples were aseptically collected into sterile plastic tubes and preserved at $8{ }^{\circ} \mathrm{C}$ until isolation. RIF were isolated by the direct inoculation of rock fragments on Petri dishes with Dichloran rose bengal chloramphenicol agar (DRBC, Difco) and Malt yeast extract agar (MYEA, Selbmann et al. 2005). The plates were in-

\section{DNA extraction and sequencing}

Sequencing of the complete ITS rDNA region (ITS1-5.8S-ITS2) was used to delimit species of RIF's isolates and compare them with close relatives (de Hoog et al. 1999). Genomic DNA was isolated from 12 weeks old cultures grown on MEA plates at $15{ }^{\circ} \mathrm{C}$. Mycelial fragments were disrupted using the FastPrep bead beating system (MP Biomedicals, Irvine, CA, USA) and purified with a High Pure PCR Tem- scribed in this study showed high similarity with reference sequnces and could be indentified to the species level. Taxonomic position of the remaining isolates was unclear and require further investigation.

ture around $-7^{\circ} \mathrm{C}$ (Ambrožová and Láska 2016). The vegetation is represented by a great variety of terrestrial algae, cyanobacteria, lichens and mosses as the main components of communities forming Antarctic vegetation oases (Barták et al. 2015).

cubated at $15^{\circ} \mathrm{C}$ under aerobic conditions and observed after four weeks. Axenic cultures of RIF were subcultured on agar plates with 2\% Malt Extract Agar (MEA, Difco) and maintained at $-70^{\circ} \mathrm{C}$. Morphology of 12 weeks old isolates cultivated on MEA at $15^{\circ} \mathrm{C}$ was studied by microscopic observation in lactic acid using Olympus BX 50 light microscope. Microphotographs were done with a digital camera Artcam $500 \mathrm{MI}$.

plate Preparation Kit (Roche, Germany). The ITS rDNA region was amplified with the primers SR6R and LR1 (Vilgalys and Hester 1990). PCR conditions and sequencing method were performed according to Marvanová and Laichmanová (2014). Sequences obtained in this study were submitted to NCBI's GenBank nucleotide database (Table 1). 


\begin{tabular}{|c|c|c|c|}
\hline Species & Strain No. & Locality & $\begin{array}{l}\text { ITS GenBank } \\
\text { accession No. }\end{array}$ \\
\hline Aureobasidium subglaciale & CBS 123387 & $\begin{array}{l}\text { Svalbard and } \\
\text { Jan Maven Island }\end{array}$ & NR_147323.1 \\
\hline Cladosporium cladosporioides & CBS 112388 & Germany & NR_119839.1 \\
\hline Cladosporium colombiae & CBS $274.80 \mathrm{~B}$ & Colombia & NR_119729.1 \\
\hline $\begin{array}{l}\text { Cladosporium } \\
\text { verrucocladosporioides }\end{array}$ & CBS 126363 & South Korea & MH863939.1 \\
\hline Oleoguttula mirabilis & P10109 & JRI, Antarctica (1) & MW222191 \\
\hline Oleoguttula mirabilis & P10406 & JRI, Antarctica (2) & MW222211 \\
\hline Oleoguttula mirabilis & P10407 & JRI, Antarctica (2) & MW222212 \\
\hline Oleoguttula mirabilis & P10444 & JRI, Antarctica (1) & MW222225 \\
\hline Oleoguttula mirabilis & CCFEE 5522 & JRI, Antarctica & KF309972.1 \\
\hline Oleoguttula mirabilis & CBS 136102 & JRI, Antarctica & NR 144974.1 \\
\hline Oleoguttula mirabilis & EXF-13077 & Greenland Ice Sheet & MK460370.1 \\
\hline Oleoguttula mirabilis & EXF-13078 & Greenland Ice Sheet & MK460369.1 \\
\hline Oleoguttula mirabilis & EXF-13080 & Greenland Ice Sheet & MK460371.1 \\
\hline Rachicladosporium alpinum & CBS 136040 & Monte Rosa, Italy & NR 144965.1 \\
\hline Rachicladosporium americanum & CBS 124774 & Virginia, USA & MH863412.1 \\
\hline Rachicladosporium antarcticum & P10108 & JRI, Antarctica (3) & MW251711 \\
\hline Rachicladosporium antarcticum & P10377 & JRI, Antarctica (5) & MW222195 \\
\hline Rachicladosporium antarcticum & P10413 & JRI, Antarctica (4) & MW222216 \\
\hline Rachicladosporium antarcticum & CCFEE 5527 & $\begin{array}{l}\text { Antarctic Peninsula, } \\
\text { Antarctica }\end{array}$ & NR_144970.1 \\
\hline Rachicladosporium cboliae & CBS 125424 & Virginia, USA & NR_156538 \\
\hline Rachicladosporium corymbiae & CBS 145087 & Ghana & NR_-161143 \\
\hline Rachicladosporium eucalypti & CPC 23241 & Ethiopia & NR_155718.1 \\
\hline Rachicladosporium inconspicuum & CBS 136043 & Monte Rosa, Italy & NR_144966 \\
\hline Rachicladosporium iridis & CBS 282.49 & Netherlands & NR_169891.1 \\
\hline Rachicladosporium luculiae & CBS 121620 & Auckland, New Zealand & NR_160222 \\
\hline Rachicladosporium mcmurdoi & CBS 119432 & $\begin{array}{l}\text { McMurdo Dry Valleys, } \\
\text { Antarctica }\end{array}$ & NR_144967.1 \\
\hline Rachicladosporium monterosium & CBS 137178 & Monte Rosa, Italy & NR_144968.1 \\
\hline Rachicladosporium paucitum & CBS 136041 & Trento, Italy & NR_144969 \\
\hline Rachicladosporium pini & CBS 129525 & Netherlands & JF951145.1 \\
\hline Toxicocladosporium banksiae & CBS 128215 & Australia & NR 152322.1 \\
\hline Toxicocladosporium irritans & CBS 185.58 & Suriname & NR_152316.1 \\
\hline Toxicocladosporium strelitziae & CBS 132535 & South Africa & NR_111765.1 \\
\hline Pseudotaeniolina globosa & CBS 109889 & Italy & $\mathrm{MH} 862844.1$ \\
\hline
\end{tabular}

Table 1. List of isolates used in the study. Isolates investigated in this work are highlighted in bold. Strains isolated from the rock are highlighted in yellow. Notes: JRI - James Ross Island, Antarctica. Numbers in parentheses shows sampling sites displayed in Fig. 1.

Phylogenetic analysis

The megablast search (Zhang et al. 2000) of ITS rDNA sequences was used to identify highly similar species to RIF isolates in the NCBI's GenBank nucleotide database. The ITS rDNA sequences dataset for phylogenetic analysis involved $33 \mathrm{nu}-$ cleotide sequences of which 26 sequences of close related taxa were retrieved from 
the NCBI's GenBank (Table 1). They were aligned by the ClustalW program (Thompson et. al. 1994) and manually checked and assembled. The phylogenetic analysis and dendrogram construction was conducted using MEGA X software (Kumar et al. 2018). The evolutionary history was inferred by using the Maximum Likelihood method and Jukes-Cantor model and genetic distances were estimated using the Maximum Composite Likelihood (MCL) method (Jukes and Cantor 1969). Branch support was tested by 1000 replications in the bootstrap test (Felsenstein 1985).

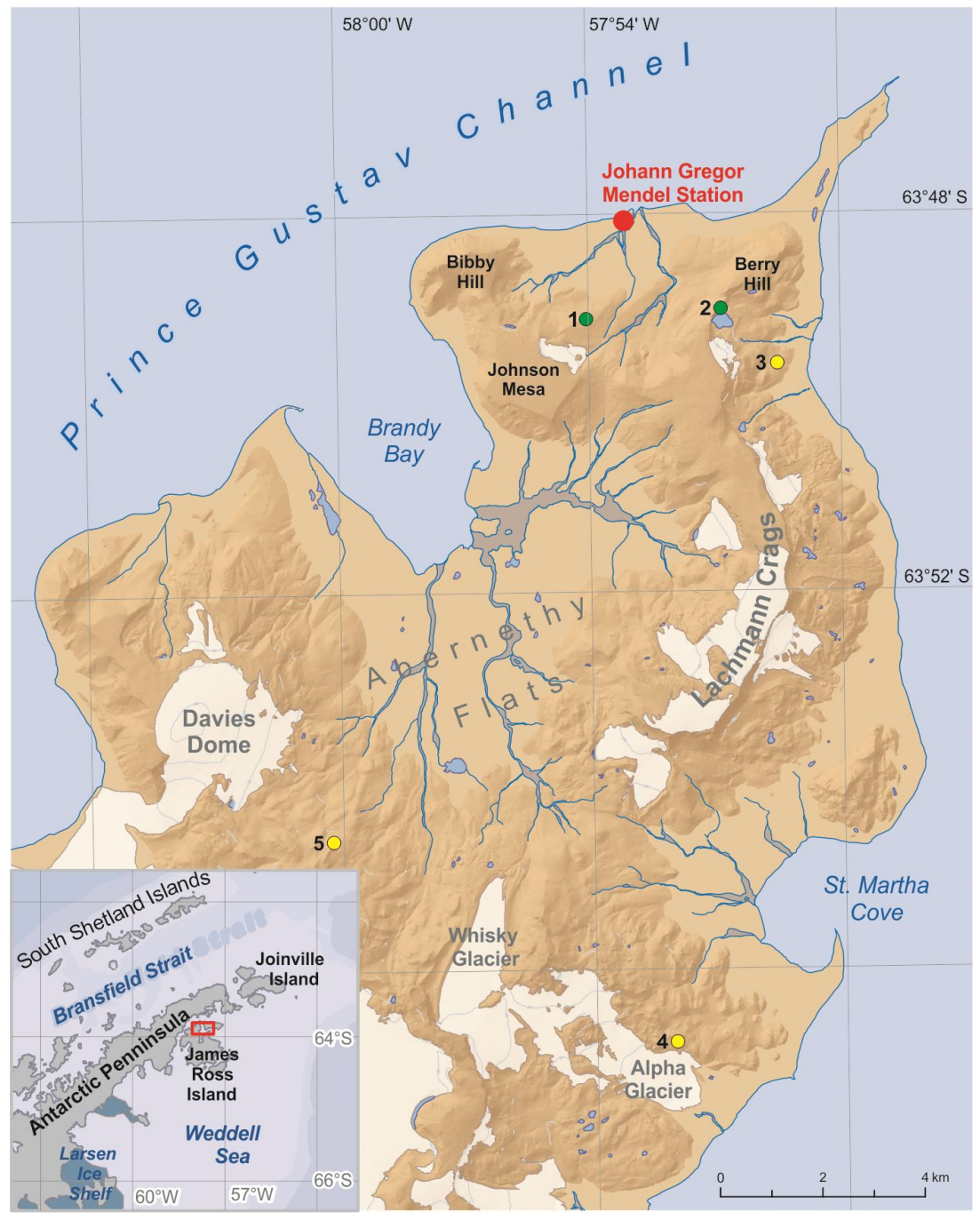

Fig. 1. Modified map of James Ross Island - Northern part ([1] - Czech Geological Survey 2009) showing the sampling sites of Oleoguttula mirabilis (green points) and Rachicladosporium antarcticum (yellow points) analysed strains. Notes: (1) - northeast side of Johnson Mesa, (2) - southeast side of Lachman Crags, (3) - rock outcrop of Sekyra Peak, (4) - Panorama Pass, (5) - near Alpha Glacier. 


\section{Results and Discussion}

Comparison of obtained ITS rDNA sequences within the nucleotide NCBI database showed $R$. antarcticum CCFEE 5527 (NR_144970.1) as 100\% identical with RIF isolate P10108 and highly similar with RIF isolates P10377 and P10413 (99.59\%), followed by Rachicladosporium monterosium CBS 137178 (NR_144961.1, 98.56\%) and R. mcmurdoi CBS 119432 (NR 144967.1, 97.33\%). The remaining four RIF isolates (P10109, P10406, P10407, P10444) showed $100 \%$ sequence similarity with $O$. mirabilis CCFEE 5522 (KF309973.1) and 99\% sequence similarity with $O$. mirabilis $\mathrm{CBS}$ 136102 (NR_144974.1) and O. mirabilis strains EXF-13077, EXF-13078, EXF13080. The genus Oleoguttula displayed very distinct ITS sequences from other sequences in the nucleotide NCBI database and Pseudotaeniolina globosa CBS 109889 (MH862844) isolated from stone of church in Italy was found as the phylogenetically closest relative (similarity $89.77 \%$ ).

Phylogenetic analysis and Maximum Likelihood phylogenetic tree constructed using ITS rDNA sequences (Fig. 3) clearly showed the phylogenetic relation of three RIF isolates P10108, P10377 and P10413 from James Ross Island to $R$. antarcticum (Rachicladosporium clade) and P10109, P10406, P10407 and P10444 RIF isolates to O. mirabilis (Oleoguttula clade).

The three RIF isolates assigned in the Rachicladosporium clade clustered with the reference ITS sequences of 13 Rachicladosporium species. Cladosporium spp. and Toxicocladosporium spp. were included in the phylogenetic tree construction as closely related genera of the family Cladosporiaceae. Analysed RIF isolates P10108, P10377 and P10413 were clustered with $R$. antarcticum CCFEE 5527 (NR_144970.1) described from Antarctic Peninsula (Egidi et al. 2014) with 91\% bootstrap support. The evolutionary divergences among strains placed in the sepa- rate subbranch, including $R$. antarcticum, $R$. monterosium and $R$. mcmurdoi varied from 1.1 to $2.2 \%$, while the evolutionary divergences among all Rachicladosporium species were in the range of $1.1-15.4 \%$ (data not showed). Pairwise distance calculation showed a minor percentage of nucleotide differences $(0-0.5 \%)$ in the case of intraspecific variation in $R$. antarcticum.

Rachicladosporium antarcticum isolates were collected from three distant localities of James Ross Island (Fig. 1). The closest related species $R$. monterosium was isolated from Monte Rosa in the Italian Alps and $R$. mcmurdoi was collected from McMurdo Dry Valleys in Southern Victoria Land, Antarctica. These species are difficult to identify based on morphology because they are scarcely differentiated. They all develop brown, branched hyphae but $R$. monterosium often forms hyphae in strands with anastomosis and $R$. antarcticum produces torulose hyphae enteroblastically proliferating. Rachicladosporium mcmurdoi develops 1 -2-celled conidia by arthric secession, while the formation of conidia or chlamydospor-like cells were not observed even after prolonged incubation of $R$. monterosium and $R$. antarcticum (Egidi et al. 2014). Studied isolates developed brown, branched, torulose hyphae (Fig. 2). Colonies on MEA attained $20 \mathrm{~mm}$ in diam. after 12 weeks at $15{ }^{\circ} \mathrm{C}$. They were compact, elevated with folds, dark brown in observe and black in reverse (Fig. 2).

The Oleoguttula clade was composed of four analysed RIF isolates (P10109, P10406, P10407, P10444) collected from two different sampling sites on James Ross Island while strains of $O$. mirabilis (CBS 136102, CCFEE 5522) described by Selbmann and de Hoog and originated form James Ross Island (Egidi et al. 2014) were isolated from another locality than our isolates. 

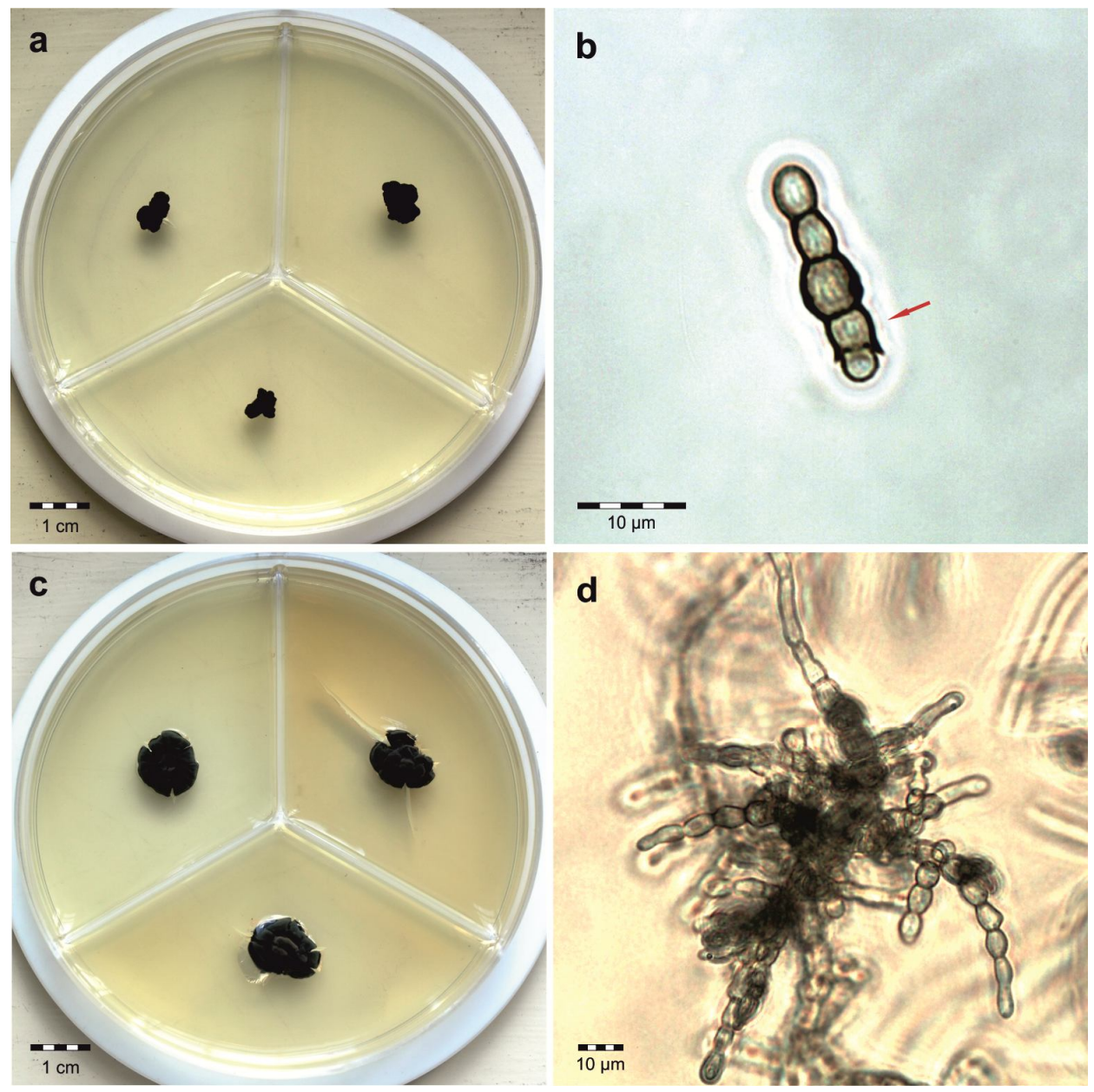

Fig. 2. a-b Oleoguttula mirabilis P10407; a - colony appearance on MEA after 12 weeks, b - wide opening, terminal phialide with conidia; c-d Rachicladosporium antarcticum P10108, $\mathbf{c}$ - colony appearance on MEA after 12 weeks, $\mathbf{d}$ - torulose, branched hyphae.

The remaining three strains (EXF13077, EXF-13078, EXF-13080) of Oleoguttula clade were originated from the Greenland ice sheet (Perini et al. 2019). The intraspecific variability of ITS sequences in $O$. mirabilis varied from 0 to $0.5 \%$. The morphology of studied isolates corresponded with the description of the type culture $O$. mirabilis CBS $136102^{\mathrm{T}}$ from Selbmann and de Hoog (Egidi et al. 2014). Colonies on MEA attained $9 \mathrm{~mm}$ in diam. after 12 weeks at $15^{\circ} \mathrm{C}$. They were black in obverse and reverse, cerebriform with irregular margin. Unicellular, micronematous phialides with wide collorattes and brown conidia were observed (Fig. 2). 


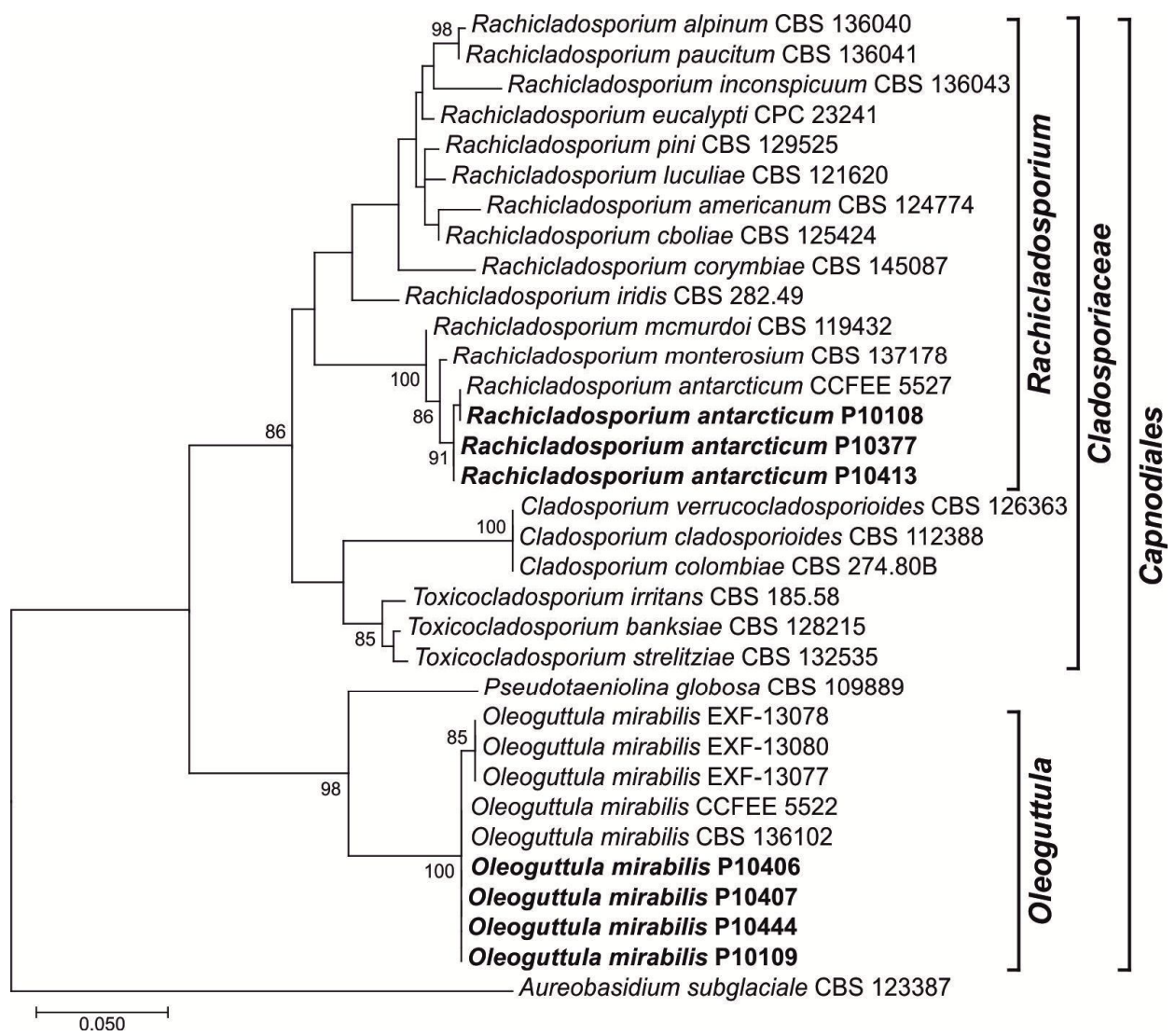

Fig. 3. Maximum Likelihood phylogenetic tree constructed using ITS rDNA sequences shows the phylogenetic position of studied Oleoguttula mirabilis and Rachicladosporium antarcticum isolates (in bold) among representaive strains of the genera Rachicladosporium and Oleoguttula. All positions containing gaps and missing data were eliminated. There were a total of 391 positions in the final dataset. Bootstrap probability values (percentages of 1000 tree replications) greater than $85 \%$ are indicated at branch points. Aureobasidium subglaciale CBS 123387 (NR 147323.1) was used as an outgroup. Bar, 0.05 substitutions per nucleotide position.

\section{Conclusion}

Oleoguttula mirabilis and Rachicladosporium antarcticum, two psychrophilic species inhabiting rocks in Antarctica were identified based on sequences similarity and phylogenetic analysis of ITS rDNA region supported by morphological data. Both species were repeatedly collected from different parts of James Ross Island, which indicates their distribution across the deglaciated part of Ulu Peninsula. 


\section{References}

AmbrožovÁ, K., LÁsKA, K. (2016): The air temperature change on James Ross Island within the context of the Antarctic Peninsula. In: A. Nováček (ed.): Sborník príspěvki̊ z výroční konference ČGS, 5-7 September 2016, Jihočeská Univerzita, České Budějovice, pp. 20-25. (In Czech).

BARTÁK, M., VÁcZi, P., Stachoñ, Z. and KubešovÁ, S. (2015): Vegetation mapping of moss dominated areas of northern part of James Ross Island (Antarctica) and a suggestion of protective measures. Czech Polar Reports, 5(1): 75-87.

Crous, P. W., Braun, U., Schubert, K. and Groenewald, J. Z. (2007): Delimiting Cladosporium from morphologically similar genera. Studies in Mycology, 58: 33-56.

Crous, P. W., Schumacher, R. K., Akulov, A., Thangavel, R., Hernández-Restrepo, M., Carnegie, A. J., Cheewangkoon, R., Wingfield, M. J., Summerell, B. A., Quaedvlieg, W., Coutinho, T. A., Roux, J., Wood, A. R., Giraldo, A. and Groenewald, J. Z. (2019): New and Interesting Fungi. 2. Fungal Systematics and Evolution, 3: 57-134.

De Hoog, S., Zalar, P., Urzì, C., De Leo, F., Yurlova, N. and Sterflinger, K. (1999): Relationships of dothideaceous black yeasts and meristematic fungi based on 5.8S and ITS2 rDNA sequence comparison. Studies in Mycology, 43: 31-37.

Egidi, E., De Hoog, G. S., Isola, D., Onofri, S., Quaedvlieg, W., De Vries, M., Verkley, G. J. M., Stielow, J. B., Zucconi, L. and Selbmann, L. (2014): Phylogeny and taxonomy of meristematic rock-inhabiting black fungi in the Dothideomycetes based on multilocus phylogenies. Fungal Diversity, 65: 127-165.

FelsensteIn, J. (1985): Confidence limits on phylogenies: An approach using the bootstrap. Evolution, 39: 783-791.

FriedmanN, E.I. (1982): Endolithic Microorganisms in the Antarctic Cold Desert. Science, 215: 1045-1053.

GorbushinA, A. (2007): Life on the rocks. Environmental microbiology, 9: 1613-1631.

Isola, D., Zucconi, L., Onofri, S., Caneva, G., De Hoog, G. S. and Selbmann, L. (2015): Extremotolerant rock inhabiting black fungi from Italian monumental sites. Fungal Diversity, 76: 75-96.

Jukes, T. H., CANTOR, C. R. (1969): Evolution of protein molecules. In: H. N. Munro (ed.): Mammalian Protein Metabolism, Academic Press, New York, pp. 21-132.

Kumar, S., Stecher, G., Li, M., Knyaz, C. and Tamura, K. (2018): MEGA X: Molecular Evolutionary Genetics Analysis across computing platforms. Molecular Biology and Evolution, 35: $1547-1549$.

MarvanovÁ, L., Laichmanová, M. (2014): Campylospora leptosoma sp. nov. and characteristics of Campylospora spp., based on morphology and on ITS sequences. Mycosphere, 5(2): 245261.

Perini, L., Gostinčar, C., Anesio, A. M., Williamson, C., Tranter, M. and Gunde-Cimerman, N. (2019): Darkening of the Greenland Ice Sheet: Fungal Abundance and Diversity Are Associated With Algal Bloom. Front Microbiology, 10: 557. https://doi.org/10.3389/fmicb. 2019.00557

Quaedvlieg, W., Binder, M., Groenewald, J. Z., Summerell, B. A., Carnegie, A. J., Burgess, T. I. and Crous, P. W. (2014): Introducing the Consolidated Species Concept to resolve species in the Teratosphaeriaceae. Persoonia Molecular Phylogeny and Evolution of Fungi, 33: 1-40.

Ruibal, C., Gueidan, C., Selbmann, L., Gorbushina, A. A., Crous, P. W., Groenewald, J. Z., Muggia, L., Grube, M., Isola, D., Schoch, C. L., Staley, J. T., Lutzoni, F. and De Hoog, G. S. (2009): Phylogeny of rock-inhabiting fungi related to Dothideomycetes. Studies in Mycology, 64: 123-133.

Ruibal, C., Platas, G. and Bills, G. F. (2008): High diversity and morphological convergence among melanised fungi from rock formations in the Central Mountain System of Spain. Persoonia Molecular Phylogeny and Evolution of Fungi, 21: 93-110.

Ruibal, C., Platas, G. and Bills, G. (2005): Isolation and characterization of melanized fungi from limestone formation in Mallorca. Mycological Progress, 4: 23-38. 
Selbmann, L., De Hoog, G. S., Mazzaglia, A., Friedmann, E. I. and Onofri, S. (2005): Fungi at the edge of life: cryptoendolithic black fungi from Antarctic desert. Studies in Mycology, 51: $1-32$.

Selbmann, L., De Hoog, G. S., Zucconi, L., Isola, D., Ruisi, S., Gerrits Van Den Ende, A. H., Ruibal, C., De Leo, F., UrZì, C. and OnOFRI, S. (2008): Drought meets acid: three new genera in a dothidealean clade of extremotolerant fungi. Studies in Mycology, 61: 1-20.

Selbmann, L., Grube, M., Onofri, S., Isola, D. and Zucconi, L. (2013): Antarctic Epilithic Lichens as Niches for Black Meristematic Fungi. Biology, 2: 784-797.

Selbmann, L., Isola, D., Egidi, E., Zucconi, L., Gueidan, C., De Hoog, G.S. and Onofri, S. (2014): Mountain tips as reservoirs for new rock-fungal entities: Saxomyces gen. nov. and four new species from the Alps. Fungal Diversity, 65: 167-182.

Selbmann, L., Isola, D., ZuCCONI, L. and ONOFRI, S. (2011): Resistance to UV-B induced DNA damage in extreme-tolerant cryptoendolithic Antarctic fungi: detection by PCR assays. Fungal Biology, 115: 937-944.

Sert, H. B., SÜMBÜL, H. and Sterflinger, K. (2007): Microcolonial fungi from antique marbles in Perge/Side/Termessos (Antalya/Turkey). Antonie Van Leeuwenhoek, 91: 217-227.

Sterflinger, K. (1998): Temperature and NaCl- tolerance of rock-inhabiting meristematic fungi. Antonie Van Leeuwenhoek, 74: 271-281.

Sterflinger, K. (2006): Black Yeasts and Meristematic Fungi: Ecology, Diversity and Identification. In: G. Péter, C. A. Rosa (eds.): Biodiversity and Ecophysiology of Yeasts, The Yeast Handbook. Springer, Berlin, Heidelberg, pp. 501-514.

Thompson, J. D., Higgins, D. G. and Gibson, T. J. (1994): ClUSTAL W: improving the sensitivity of progressive multiple sequence alignment through sequence weighting, positionspecific gap penalties and weight matrix choice. Nucleic Acids Research, 22: 4673-4680.

Urzì C., De Leo F., De Hoog S. and Sterflinger, K. (2000): Recent Advances in the Molecular Biology and Ecophysiology of Meristematic Stone-Inhabiting Fungi. In: O. Ciferri, P. Tiano, G. Mastromei (eds): Of Microbes and Art. Springer, Boston, MA, pp. 17-22.

Vilgalys R., HeSter M. (1990): Rapid genetic identification and mapping of enzymatically amplified ribosomal DNA from several Cryptococcus species. Journal of Bacteriolog, 172: 4238-4246.

Wollenzien, U., De Hoog, G. S., Krumbein, W. E. and Urzì, C. (1995): On the isolation of microcolonial fungi occurring on and in marble and other calcareous rocks. Science of the Total Environment, 167: 287-294.

Zhang, Z., Schwartz, S., Wagner, L. and Miller, W. (2000): A greedy algorithm for aligning DNA sequences. Journal of Computational Biology, Feb-Apr; 7(1-2): 203-14. doi: 10.1089/ 10665270050081478. PMID: 10890397.

Zhdanova, N. N., Zakharchenko, V. A., Vember, V. V. and Nakonechnaya, L. T. (2000). Fungi from Chernobyl: Mycobiota of the inner regions of the containment structures of the damaged nuclear reactor. Mycological Research, 104: 1421-1426.

Zucconi, L., Onofri, S., Cecchini, C., Isola, D., Ripa, C., Fenice, M., Ma-Donna, S., Reboleiro-Rivas, P. and Selbmann, L. (2014): Mapping the lithic colonization at the boundaries of life in Northern Victoria Land, Antarctica. Polar Biology, 39: 91-102.

\section{Web sources / Other sources}

[1] Czech Geological Survey, 2009. James Ross Island - northern part. Topographic map 1: 25 000. First edition. Praha, Czech Geological Survey. ISBN 978-80-7075-734-5. 